\title{
ANALISIS FAKTOR HOSPITALITI MASYARAKAT TERHADAP WISATAWAN DI KAWASAN KOTA BOGOR
}

\author{
Resista Vikaliana \\ Institut Sosial dan Manajemen Stiami \\ resistav31@gmail.com
}

\begin{abstract}
Abstrak. Kota Bogor memiliki fenomena alam sebagai destinasi wisata. Oleh karena itu, sampai dengan sekarang ketika memasuki masa liburan, Kota Bogor senantiasa ramai oleh wisatawan. Untuk memajukan pariwisata di Kota Bogor, sudah semestinya diperlukan fasilitas-fasilitas yang dapat menunjangnya antara lain hospitality industry. Keberadaan hospitality industry tersebut di Kota Bogor menjadi daya tarik yang sangat besar bagi wisatawan baik yang tujuannya untuk mencari hiburan maupun untuk tujuan bisnis. Berdasarkan informasi yang diperoleh oleh wisatawan atas keberadaan destinasi wisata di Kota Bogor, maka wisatawan tertarik untuk melakukan perjalanan dengan menghabiskan waktu dan biaya demi terpuaskan rasa ingin tahu. Penelitian ini dilakukan untuk mempelajari lebih lanjut dengan perumusan masalah sebagai faktorfaktor hospitaliti apa sajakah yang dapat memuaskan wisatawan yang berkunjung ke Kota Bogor?

Pendekatan penelitian yang digunakan dalam penelitian ini adalah pendekatan kuantitatif. Sedangkan jenis penelitian ini adalah penelitian deskriptif. Penelitian deskriptif bertujuan menggambarkan atau melukiskan sebuah objek penelitian. Teknik pengambilan data menggunakan data primer dan sekunder. Data primer diambil dengan menggunakan kuesioner. Kuesioner disebarkan pada 100 orang wisatawan dengan teknik pengambilan sampel cluster sampling, pada objek wisata Kebun Raya Bogor, Taman Topi/ Taman Ade Irma Suryani dan Wisata Kuliner Suryakencana. Data dianalisis menggunakan analisis faktor.

Berdasarkan hasil penelitian, dapat disimpulkan bahwa dari 24 faktor-faktor hospitaliti masyarakat yang paling berpengaruh pada kunjungan wisatawan di Kota Bogor dapat dikelompokkan menjadi 7 komponen atau variabel.
\end{abstract}

Kata Kunci: hospitaliti masyarakat, kunjungan wisatawan, Kota Bogor

Abstract. Bogor city has a natural phenomenon as a tourist destination. Therefore, until now when entering the holiday period, Bogor City is always crowded by tourists. To promote tourism in the city of Bogor, it is necessary necessary facilities that can support such as hospitality industry. The existence of hospitality industry in the city of Bogor becomes a very big attraction for tourists both for the purpose of seeking entertainment or for business purposes. Based on information obtained by tourists on the existence of tourist destinations in the city of Bogor, the tourists are interested to travel by spending time and money to satisfy curiosity.This research is conducted to learn more with the formulation of the problem as the factors of what hospitals can satisfy tourists who visit the city of Bogor?

The research approach used in this research is quantitative approach. While this type of research is descriptive research. Descriptive research aims to describe or describe a research object.Technique of taking data using primary and secondary data. Primary data were taken using questionnaire. Questionnaires were distributed to 100 travelers with sampling technique of cluster sampling, at Bogor Botanical Garden object, Taman Hat / Taman Ade Irma Suryani and Suryakencana Culinary Tour. Data were analyzed using factor analysis.

Based on the result of the research, it can be concluded that of the 24 most influential community hospital factors on tourist visit in Bogor City can be grouped into 7 components or variables.

Keywords: community hospitaliti, tourist visit, City of Bogor 


\section{PENDAHULUAN}

Kota Bogor memiliki fenomena alam sebagai destinasi wisata. Oleh karena itu, sampai dengan sekarang ketika memasuki masa liburan, Kota Bogor senantiasa ramai oleh wisatawan. Untuk memajukan pariwisata di Kota Bogor, sudah semestinya diperlukan fasilitas-fasilitas yang dapat menunjangnya antara lain hospitality industry. Keberadaan hospitality industry tersebut di Kota Bogor menjadi daya tarik yang sangat besar bagi wisatawan baik yang tujuannya untuk mencari hiburan maupun untuk tujuan bisnis.

Berdasarkan informasi yang diperoleh oleh wisatawan atas keberadaan destinasi wisata di Kota Bogor, maka wisatawan tertarik untuk melakukan perjalanan dengan menghabiskan waktu dan biaya demi terpuaskan rasa ingin tahu. Artinya, industri pariwisata merupakan industri perdagangan jasa yang memiliki mekanisme pengaturan yang kompleks karena mencakup pengaturan pergerakan wisatawan dari negara asalnya, di daerah tujuan wisata hingga kembali ke negara asalnya yang melibatkan berbagai hal seperti transportasi, penginapan, restoran, pemandu wisata, dan lain-lain. Oleh karena itu, industri pariwisata memegang peranan yang sangat penting dalam pengembangan pariwisata.

Dalam menjalankan perannya, industri pariwisata harus menerapkan konsep dan peraturan serta panduan yang berlaku dalam pengembangan pariwisata agar mampu mempertahankan dan meningkatkan jumlah kunjungan wisatawan yang nantinya bermuara pada pemberian manfaat ekonomi bagi industri pariwisata dan masyarakat lokal. Industri-industri pariwisata yang sangat berperan dalam pengembangan pariwisata adalah: biro perjalanan wisata, hotel dan restoran. Selain itu juga didukung oleh industri-industri pendukung pariwisata lainnya.

Biasa konsep ini juga terjadi pada industri perhotelan sebagai bentuk akomodasi dari pariwisata. Bahkan pola yang digagas tersebut menjadi sektor yang tumbuh paling cepat, terhitung lebih dari sepertiga dari total perdagangan jasa global (ILO, 2010). Hal ini dibuktikan oleh fakta bahwa selama 25 tahun terakhir, kedatangan wisatawan internasional terus meningkat sekitar satu persen lebih cepat dari produk domestik bruto (PDB) secara riil (ILO, 2010).

Sebagaimana dijelaskan lebih lanjut atas kesimpulan data tersebut, bahwa industri perhotelan membutuhkan standar bagi hotelnya untuk operasional, sehingga industri memiliki karakteristik tersendiri untuk memenuhi standar jasa tersebut, yaitu seperti: intangible of services, produksi dan konsumsi jasa, serta layanan secara heterogen melalui hubungan personal antara customer dengan penyedia jasa atau karyawan dari hotel tersebut sendiri.

Kota Bogor yang memiliki ragam daya tarik tersebut juga menjadi magnet bagi wisatawan untuk datang, terutama warga Ibukota Jakarta. Tak heran jika musim liburan Kota Bogor mampu meraup pendapatan dibandingkan hari-hari biasa di bidang pariwisata. Dibalik kesuksesan mencari wisatawan, hampir secara umum masyarakat mempunyai keyakinan bahwa Kota Bogor mempunyai hubungan lokatif dengan Kota Pakuan, ibukota Pajajaran. Asal-usul dan arti Pakuan terdapat dalam berbagai sumber.

Naskah Carita Waruga Guru (1750-an). Dalam naskah berbahasa Sunda Kuna ini diterangkan bahwa nama Pakuan Pajajaran didasarkan bahwa di lokasi tersebut banyak terdapat pohon Pakujajar. Sementara K.F. Holle (1869) dalam tulisan berjudul De Batoe Toelis te Buitenzorg (Batutulis di Bogor), Holle menyebutkan bahwa di dekat Kota Bogor terdapat kampung bernama Cipaku, beserta sungai yang memiliki nama yang sama. Di sana banyak ditemukan pohon paku. Jadi menurut Holle, nama Pakuan ada kaitannya dengan kehadiran Cipaku dan pohon paku. Pakuan Pajajaran berarti pohon paku yang berjajar ("op rijen staande pakoe bomen").

Adapun G.P. Rouffaer (1919) dalam Encyclopedie van Niederlandsch Indie edisi Stibbe tahun 1919. Pakuan mengandung pengertian "paku", akan tetapi harus diartikan "paku jagat" (spijker der wereld) yang 
melambangkan pribadi raja seperti pada gelar Paku Buwono dan Paku Alam. "Pakuan" menurut Fouffaer setara dengan "Maharaja". Kata "Pajajaran" diartikan sebagai "berdiri sejajar" atau "imbangan" (evenknie). Yang dimaksudkan Rouffaer adalah berdiri sejajar atau seimbang dengan Majapahit. Sekalipun Rouffaer tidak merangkumkan arti Pakuan Pajajaran, namun dari uraiannya dapat disimpulkan bahwa Pakuan Pajajaran menurut pendapatnya berarti "Maharaja yang berdiri sejajar atau seimbang dengan (Maharaja) Majapahit". Ia sependapat dengan Hoesein Djajaningrat (1913) bahwa Pakuan Pajajaran didirikan tahun 1433. Selanjutnya $H$. Ten Dam (1957) sebagai Insinyur Pertanian ingin meneliti kehidupan sosial-ekonomi petani Jawa Barat dengan pendekatan awal segi perkembangan sejarah. Dalam tulisannya, Verkenningen Rondom Padjadjaran (Pengenalan sekitar Pajajaran), pengertian "Pakuan" ada hubungannya dengan "lingga" (tonggak) batu yang terpancang di sebelah prasasti Batutulis sebagai tanda kekuasaan. Ia mengingatkan bahwa dalam Carita Parahyangan disebut-sebut tokoh Sang Haluwesi dan Sang Susuktunggal yang dianggapnya masih mempunyai pengertian "paku".

Dari model nama tersebut, diperoleh jawaban bahwa faktor hospitaliti memang perlu dikembangkan dalam dunia pariwisata Kota Bogor. Antara lain karena asal usul nama terkait dengan kerajaan yang berarti adanya layanan di dalamnya. Berdasarkan hal tersebut, penelitian ini dilakukan untuk mempelajari lebih lanjut dengan perumusan masalah sebagai faktor-faktor hospitaliti apa sajakah yang dapat memuaskan wisatawan yang berkunjung ke Kota Bogor?

\section{KAJIAN PUSTAKA}

Faktor yang ada pada hospitaliti pariwisata pada dasarnya mengacu dari teori penawaran dan permintaan yang disediakan oleh pengelola destinasi wisata. Sukirno (1985: 51) menyampaikan bahwa secara sederhana teori penawaran dan permintaan membahas mengenai interaksi antara penjual dan pembeli dalam menentukan harga suatu barang dan jumlah barang yang akan ditawarkan. Sehingga bisnis pariwisata sering disebut sebagai sebuah industri jasa karena adanya serangkaian proses aktivitas atau kegiatan produksi yang menghasilkan nilai tambah dan produknya bersifat tidak nyata, serta menawarkan keramahtamahan (hospitality) (Sunaryo, 2013).

Keterkaitan sistemik dari berbagai aktivitas kepariwisataan menggambarkan interaksi antara dua komponen pokok kepariwisataan yaitu komponen produk dan komponen pasar. Bagian komponen produk wisata yang juga sering disebut sebagai komponen pokok sebuah destinasi antara lain daya tarik wisata yang menawakan keindahan alam,keunikan budaya atau minat khusus, fasilitas pariwisata seperti akomodasi atau rumah makan, aksesibilitas, moda transpotasi yang tersedia, fasilitas pendukung lainnya, dan masyarakat sebagai tuan rumah destinasi.

Sedangkan dari bagian komponen pasar biasanya dibagi menjadi dua segmen yaitu pasar wisatawan domestik dan pasar wisatawan internasional. Pada komponen ini sangat dipengaruhi oleh faktor-faktor dari wisatawan seperti motivasi dan faktor penentu pribadinya dalam memilih suatu aktivitas pariwisata di suatu destinasi. Usaha akomodasi merupakan bagian dari komponen produk suatu destinasi dalam rangka memenuhi kebutuhan komponen pasar. Dalam mengembangkan pariwisata di suatu daerah sangat tergantung kepada kemampuan perencana dalam mengintegrasikan kedua sisi tersebut secara berimbang ke dalam sebuah rencana pengembangan pariwisata.

Menurut Honner dan Swarbrooke (2007)faktor-faktor yang menentukanpengambilan keputusan destinasi wisata dapat dibagi menjadi dua yaitu faktorfaktor yang menentukan apakah konsumen akan bisa mengambil liburan atau tidak dan faktor-faktor yang menentukan jenis tipe perjalanan dan pengalaman apabila liburan wisata diambil oleh mereka. Kemudian dari dua jenis faktor tersebut mereka membagi lagi menjadi faktor-faktor yang bersifat personal bagi seorang wisatawan dan faktor-faktor 
Resista Vikaliana, Analisis Faktor Hospitaliti Masyarakat Terhadap Wisatawan...

yang bersifat eksternal bagi wisatawan seperti

yang terlihat pada gambar berikut

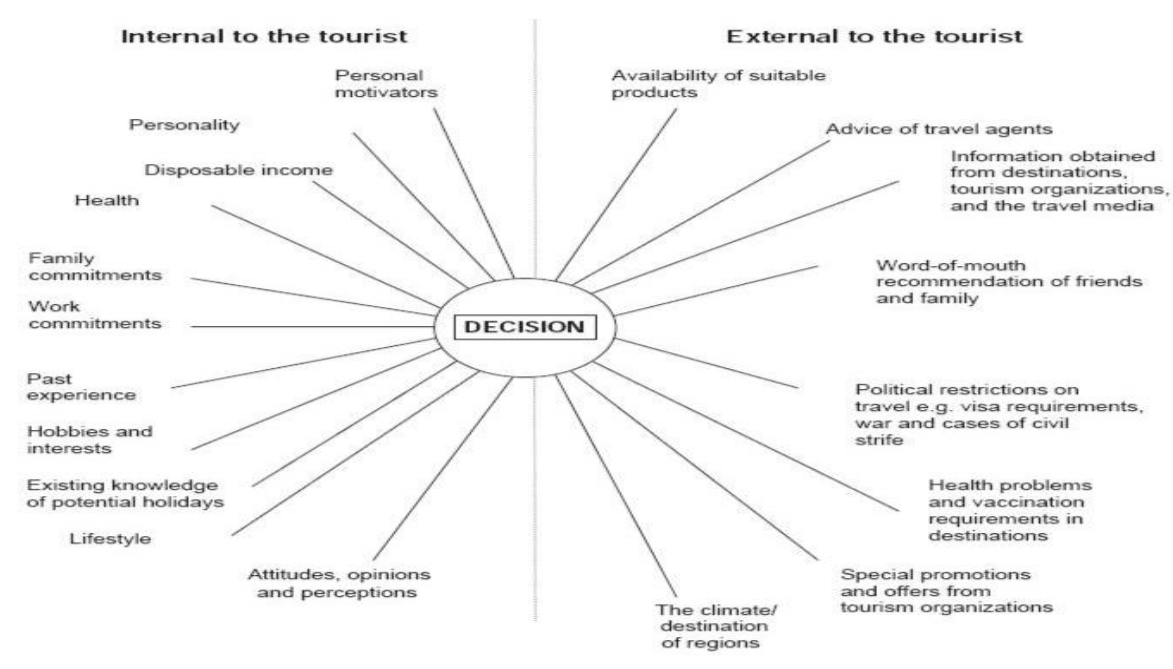

\section{Gambar 1. Faktor-Faktor Yang Mempengaruhi Keputusan Wisata (Honner\& Swarbrooke)}

Goeldner dan Ritchie (2012) juga menambahkan faktor-faktor yang mempengaruhi keputusan pemilihan destinasi wisata dengan memasukkan elemen-elemen fasilitas utama dan pendukung pariwisata, seperti akomodasi, makanan dan minuman, hotel dll-nya. Mereka juga menambahkan bahwa transportasi serta akses jalan juga memberikan pengaruh yang signifikan terhadap keputusan pemilihan destinasi wisata, karena beberapa segmen ada yang tidak menyukai tempat-tempat yang sukar untuk ditempuh, walaupun beberapa dari mereka juga ada yang menyukai tantangan. Selain faktor-faktor diatas harga paket wisata dan event-event/hiburan-hiburan berbasis pariwisata dan teknologi pendukung semisal internet dan teknologi informasi juga mendapat perhatian dari wisatawan dalam penentuan destinasi wisata. Gambar 4. akan terlihat detil faktor-faktor yang mempengaruhi seorang wisatawan dalam pemilihan destinasi wisata.

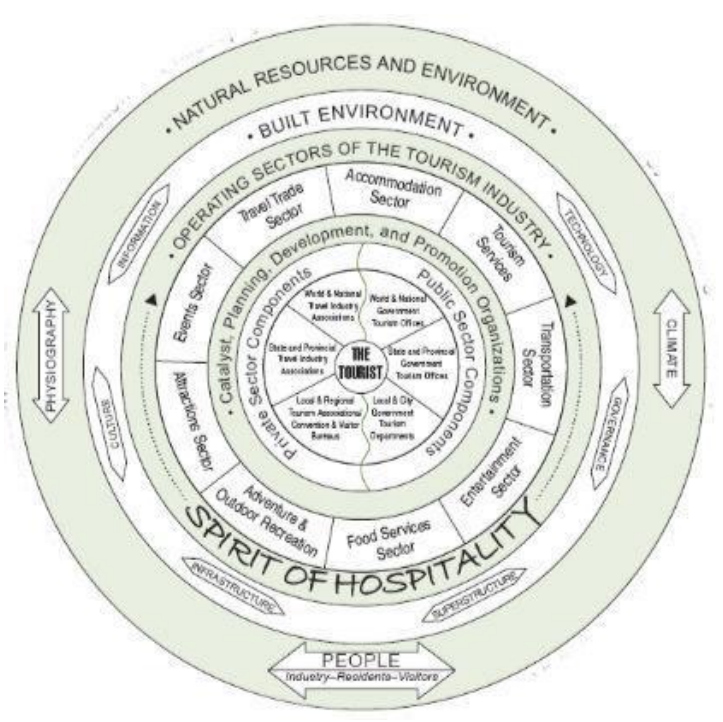

Gambar 4. Faktor-Faktor Yang Mempengaruhi Keputusan Wisata (Goeldner \& Ritchie)

Dalam arti, bagaimana menyeimbangkan antara kedua sisi tersebut, agar tidak terjadi kelebihan produk sedangkan kunjungan wisatawan semakin menurun. Begitu pula halnya dengan pembangunan sarana akomodasi di Kota Bogor, agar sesuai dengan 
kunjungan wisatawan sehingga dapat meningkatkan tingkat hunian hotel atau homestay dan akan lebih bagus bila diikuti dengan lama tinggal dan pengeluaran wisatawan yang semakin banyak.

Namun saat ini, perkembangan usaha wisata tersebut juga menimbulkan masalah baru yaitu adanya persaingan antar-pengusaha hotel. Persaingan hotel tidak saja terjadi antara usaha pariwisata, namun juga sumber daya yang ada di dalam usaha wisata itu sendiri. Dengan demikian, perlu adanya suatu strategi dalam mengantispasi situasi semacam ini. Selain melakukan promosi kepada pasar yang dituju, bekerja sama dengan berbagai pihak yang memiliki kepentingan di dalam akomodasi dan transportasi juga melakukan koordinasi yang baik sehingga sangat penting untuk selalu meningkatkan kemampuan dalam mengelola usaha wisata sesuai perkembangan zaman yang diminati oleh wisatawan.

Kriteria dalam memanfaatkan ruang sebagai pemenuhan faktor kawasan pariwisata, maka disediakan juga unsur sarana dan prasarana. Dimana terdapat objek dan daya tarik wisata yang diatur oleh kebijakan pemerintah sesuai dengan kapasitas waktu yang dibutuhkan. Ini pula yang menjadi daya tarik Kota Bogor ketika sudah bersinggungan dengan strategi menarik minat wisatawan untuk berkunjung.

\section{TUJUAN DAN MANFAAT PENELITIAN}

Penelitian ini bertujuan untuk mengetahui faktor-faktor hospitaliti yang mempengaruhi kunjungan wisatawan ke Kota Bogor. Dari faktor-faktor tersebut diharapkan dapat dikembangkan oleh semua stakeholder pariwisata Kota Bogor.

Manfaat yang diharapkan dari penelitian ini adalah model yang dihasilkan dapat diaplikasikan secara luas. Namun, secara spesifik, manfaat diharapkan:
1. Bagi bidang ilmu pengetahuan. Penelitian ini menjadi bahan penambah wawasan dan pengetahuan bagi masyarakat luas, khususnya dalam bidang faktor hospitaliti pariwisata. Karena pengaplikasian model dapat menjadi salah satu alternatif pengembangan dari faktor hospitaliti pada suatu destinasi pariwisata yang ada secara optimal.

2. Bagi peneliti selanjutnya. Penelitian ini dapat menjadi bahan referensi bagi pihakpihak yang hendak mengadakan penelitian lanjutan mengenai faktor hospitaliti yang pada gilirannya masyarakat lokal dapat memetik manfaat secara ekonomi dengan optimal.

\section{METODOLOGI PENELITIAN}

Pendekatan penelitian yang digunakan dalam penelitian ini adalah pendekatan kuantitatif. Sedangkan jenis penelitian ini adalah penelitian deskriptif. Penelitian deskriptif bertujuan menggambarkan atau melukiskan sebuah objek penelitian.

Teknik pengambilan data menggunakan data primer dan sekunder. Data primer diambil dengan menggunakan kuesioner. Kuesioner disebarkan pada 100 orang wisatawan dengan teknik pengambilan sampel cluster sampling. Berikut rinciannya:

Kebun Raya Bogor

$$
\text { : } 60 \text { orang }
$$

Taman Topi/ Taman Bermain Ade Irma Suryani : 20 orang

Wisata Kuliner Suryakencana

$$
\text { : } 20 \text { orang }
$$

Penelitian ini dianalisis menggunakan analisis faktor. Data yang diperoleh diolah dengan bantuan software pengolah data IBM SPSS 24.

Faktor-faktor hospitaliti masyarakat yang diduga mempengaruhi kunjungan wisatawan ke Kota Bogor s terlihat pada Tabel 1 
Resista Vikaliana, Analisis Faktor Hospitaliti Masyarakat Terhadap Wisatawan...

Tabel 1. Definisi Operasional Penelitian

\begin{tabular}{llrl}
\hline Var & \multicolumn{1}{c}{ Faktor } & Var & \multicolumn{1}{c}{ Faktor } \\
\hline $\mathbf{X 1}$ & Motivasi Personal & X13 & Hobi dan ketertarikan \\
\hline $\mathbf{X 2}$ & Ketersediaan obyek dan produk wisata & $\mathbf{X 1 4}$ & Pengalaman masa lalu \\
\hline $\mathbf{X 3}$ & rekomendasi dari Travel Agent & $\mathbf{X 1 5}$ & Komitmen terhadap kerja \\
\hline $\mathbf{X 4}$ & $\begin{array}{l}\text { Informasi destinasi wisata dari organisasi } \\
\text { pariwisata dan travel agent }\end{array}$ & $\mathbf{X 1 6}$ & Komitmen terhadap keluarga \\
\hline $\mathbf{X 5}$ & Words of mouth & $\mathbf{X 1 7}$ & Kesehatan personal \\
\hline $\mathbf{X 6}$ & Kondisi politik dan keamanan & $\mathbf{X 1 8}$ & Tingkat pendapatan \\
\hline $\mathbf{X 7}$ & Kondisi higeanitas lingkungan & $\mathbf{X 1 9}$ & Kepribadian \\
\hline $\mathbf{X 8}$ & Special promo dari organisasi pariwisata atau & $\mathbf{X 2 0}$ & Transportasi \& akses jalan \\
& travel agent & & \\
\hline $\mathbf{X 9}$ & Cuaca dan iklim & $\mathbf{X 2 1}$ & Fasilitas utama dan pendukung \\
\hline $\mathbf{X 1 0}$ & Sikap,opini \& persepsi & $\mathbf{X 2 2}$ & Harga paket wisata \\
\hline $\mathbf{X 1 1}$ & Gaya hidup & $\mathbf{X 2 3}$ & Event-Event dan hiburan \\
\hline $\mathbf{X 1 2}$ & Pengetahuan saat ini tentang destinasi wisata & $\mathbf{X 2 4}$ & Teknologi pendukung (internet dan \\
& & & teknologi informasi) \\
\hline
\end{tabular}

\section{HASIL DAN PEMBAHASAN}

Penelitian "Analisis Faktor-Faktor Yang Mempengaruhi Keputusan Pemilihan Destinasi Wisata Bagi Wisatawan Domestik Nusantara" bertujuan untuk menemukan faktor-faktor yang dianggap paling penting atau dominan oleh para wisatawan domestik nusantara pada saat menentukan suatu destinasi wisata. Apabila kita dapat menentukan faktor-faktor yang dominan dalam penentuan destinasi wisata, tentu saja akan mampu memberikan insight bagi stakeholder dalam penyusunan strategi pemasaran dan promosi pariwisata yang sesuai dengan kebutuhan dan keinginan konsumennya - wisatawan domestik nusantara.

Penelitian melakukan kajian dari berbagai sumber dan memasukkan 24 faktor yang biasanya dipertimbangkan oleh para wisatawan dalam menentukan destinasi wisata, yaitu sebagai berikut: Motivasi Personal (X1), Ketersediaan Obyek \& Produk Wisata (X2), Rekomendasi dari Travel Agent (X3), Informasi dari destinasi wisata dari organisasi pariwisata dan travel agent (X4), Words of Mouth atau rekomendasi dari teman, kerabat dan kolega (X5), Kondisi Politik dan Keamanan di destinasi wisata (X6), Kondisi higienitas/kebersihan dan lingkungan di destinasi wisata (X7), Special Promo dari Organisasi pariwisata atau travel agent (X8), Cuaca dan Iklim (X9), Sikap, opini dan persepsi terhadap destinasi wisata (X10), Gaya Hidup (X11), Pengetahuan saat ini tentang Destinasi Wisata (X12), Hobi dan Ketertarikan (X13), Pengalaman masa lalu (X14), Komitmen terhadap kerja (X15), Komitmen terhadap keluarga (X16), Kesehatan personal (X17), Tingkat Pendapatan (X18), Kepribadian (X19), Transportasi \& Akses Jalan (X20), Fasilitas utama dan pendukung (X21), Harga paket wisata (X22), Event dan hiburan di destinasi wisata (X23), Teknologi Pendukung seperti Internet dan teknologi informasi lainnya (X24). Ke- 24 faktor tersebut kemudian dilakuan pengujian Analisis Faktor dengan bantuan software olah data IBM SPSS versi 24.

Hasil olah data tersaji berikut ini 
ISSN 1411-0830

Tabel 1. Hasil Uji KMO and Bartlett's

KMO and Bartlett's Test

\begin{tabular}{llr}
\multicolumn{2}{l}{ Kaiser-Meyer-Olkin Measure of Sampling Adequacy. } & .805 \\
\hline Bartlett's Test of Sphericity & Approx. Chi-Square & 931.146 \\
\cline { 2 - 3 } & Df & 276 \\
\hline Sig. & .000
\end{tabular}

Kaiser-Meyer -Olkin diperoleh nilai KMO MSA sebesar 0,805 dengan tingkat signifikansi 0,000 . Karena nilai MSA>0,5 dan signifikansi $<0,05$, artinya atribut yang ada dapat dilanjutkan ke tahap analisis selanjutnya. Pada tabel anti image, faktor yang memiliki anti image correlation $<0,5$, dikeluarkan dan dilakukan pengujian ulang (tabel ada pada lampiran).

Pada tabel Total Variance Explained berikut ini, menjelaskan atribut ke dalam beberapa faktor. Dari tabel terlihat, ada 7 faktor yang terbentuk yang dianggap paling baik meringkas 24 atribut.

Tabel 2 Total Variance Explained

\begin{tabular}{|c|c|c|c|c|c|c|c|c|c|}
\hline \multirow{2}{*}{$\mathrm{nt}$} & \multicolumn{2}{|c|}{ Initial Eigenvalues } & & \multicolumn{3}{|c|}{ ion Sums of Squared Loadings } & \multicolumn{3}{|c|}{ tion Sums of Squared Loadings } \\
\hline & al & xriance & ative $\%$ & al & ariance & lative \% & stal & ariance & ative $\%$ \\
\hline 1 & 7.45 & 31.042 & 31.042 & 7.45 & 31.042 & 31.042 & 3.049 & 12.705 & 12.705 \\
\hline 2 & 1.71 & 7.125 & 38.167 & 1.71 & 7.125 & 38.167 & 2.575 & 10.729 & 23.434 \\
\hline 3 & 1.524 & 6.35 & 44.518 & 1.524 & 6.35 & 44.518 & 2.363 & 9.847 & 33.281 \\
\hline 4 & 1.438 & 5.993 & 50.511 & 1.438 & 5.993 & 50.511 & 2.243 & 9.347 & 42.628 \\
\hline 5 & 1.307 & 5.445 & 55.956 & 1.307 & 5.445 & 55.956 & 2.012 & 8.382 & 51.01 \\
\hline 6 & 1.226 & 5.109 & 61.065 & 1.226 & 5.109 & 61.065 & 1.86 & 7.749 & 58.76 \\
\hline 7 & 1.005 & 4.189 & 65.253 & 1.005 & 4.189 & 65.253 & 1.559 & 6.494 & 65.253 \\
\hline 8 & 0.919 & 3.83 & 69.083 & & & & & & \\
\hline 9 & 0.833 & 3.47 & 72.554 & & & & & & \\
\hline 10 & 0.757 & 3.153 & 75.706 & & & & & & \\
\hline 11 & 0.722 & 3.007 & 78.714 & & & & & & \\
\hline 12 & 0.69 & 2.875 & 81.589 & & & & & & \\
\hline 13 & 0.592 & 2.466 & 84.055 & & & & & & \\
\hline 14 & 0.58 & 2.416 & 86.471 & & & & & & \\
\hline 15 & 0.503 & 2.096 & 88.567 & & & & & & \\
\hline 16 & 0.44 & 1.835 & 90.402 & & & & & & \\
\hline 17 & 0.412 & 1.715 & 92.117 & & & & & & \\
\hline 18 & 0.381 & 1.586 & 93.703 & & & & & & \\
\hline 19 & 0.332 & 1.385 & 95.088 & & & & & & \\
\hline 20 & 0.313 & 1.305 & 96.394 & & & & & & \\
\hline 21 & 0.276 & 1.149 & 97.542 & & & & & & \\
\hline 22 & 0.219 & 0.913 & 98.455 & & & & & & \\
\hline 23 & 0.212 & 0.883 & 99.338 & & & & & & \\
\hline 24 & 0.159 & 0.662 & 100 & & & & & & \\
\hline
\end{tabular}

Method: Principal Component Analysis. 
Pengelompokan faktor-faktor menjadi 7 faktor terlihat pula pada grafik berikut ini.
Terdapat 7 faktor pada garis yang memiliki tingkat kemiringan berbeda.

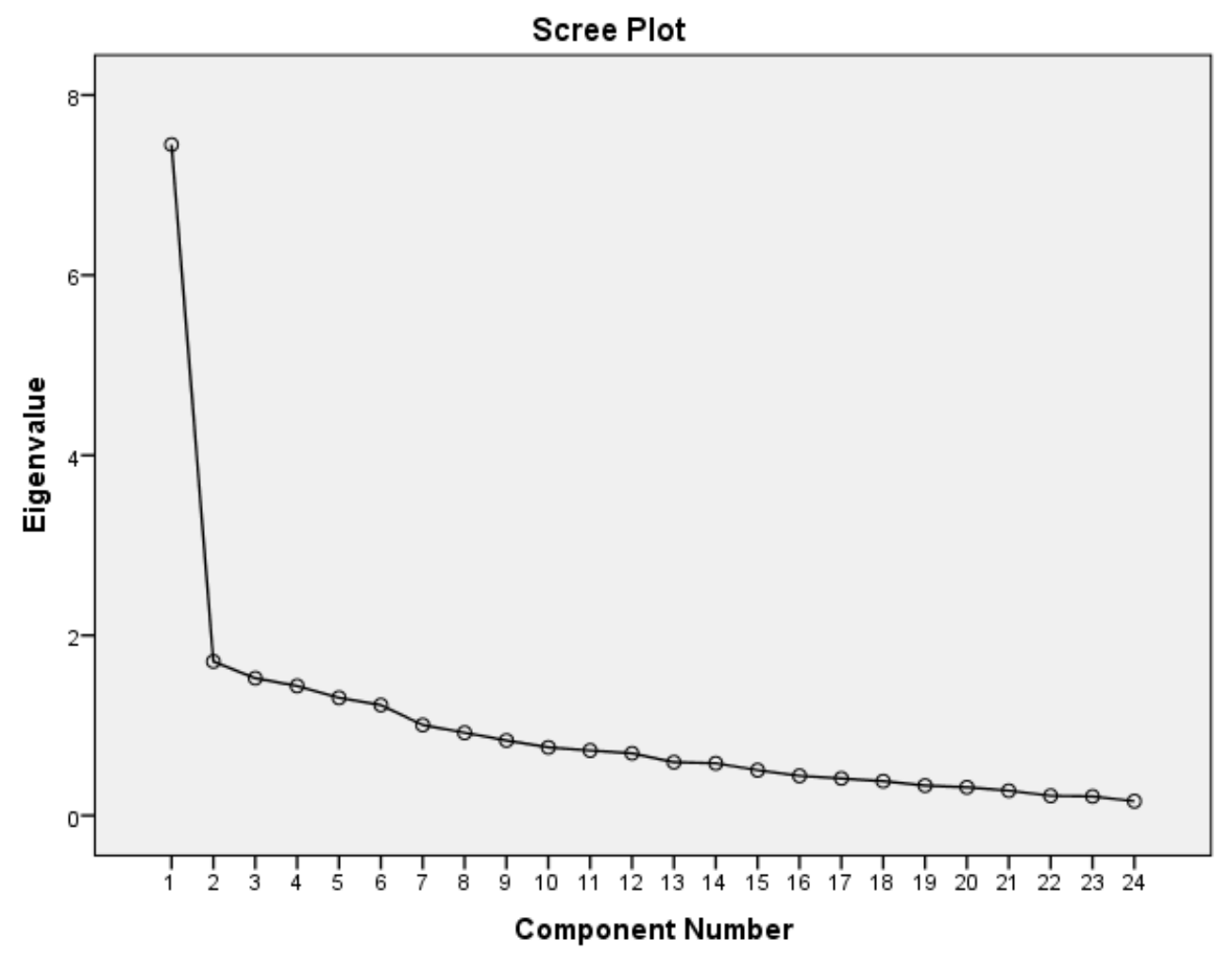

Gambar 3 Grafik Scree Plot Analisis Faktor

Sedangkan pada Tabel saran berikut, masingmasing faktor nt besaran masing-masing komponen. Nilai yang terbesar pada setiap faktor, merupakan nilai untuk pengelompokan komponen/ faktor terpilih. Pada tabel, nilai terbesar diberi latar belakang abu-abu.Lihat Tabel 3. sebagai berikut:

Interpretasi dari tabel 3 adalah 1. Komponen 1 terdiri atas faktor 5,6 , $7,8,15,18$ dan 22 yaitu:

Words of Mouth atau rekomendasi dari teman, kerabat dan kolega (X5), Kondisi Politik dan Keamanan di destinasi wisata (X6), Kondisi higienitas/kebersihan dan lingkungan di destinasi wisata (X7), Special Promo dari Organisasi pariwisata atau travel agent (X8), Komitmen terhadap kerja (X15), Tingkat Pendapatan (X18) dan Harga paket wisata (X22).

2. Komponen 2 terdiri atas faktor 1, 11, 13, 14, 19, dan 21 yaitu:

Motivasi Personal (X1), Gaya Hidup (X11), Hobi dan Ketertarikan (X13), Pengalaman masa lalu (X14), Kepribadian (X19) dan Fasilitas utama dan pendukung (X21)

3 . Komponen 3 terdiri atas faktor 2,3, dan 4 yaitu:

Ketersediaan Obyek dan Produk Wisata (X2), Rekomendasi dari Travel Agent (X3), Informasi dari destinasi wisata dari organisasi pariwisata dan travel agent (X4).

4. Komponen 4 terdiri atas faktor 9, 10, dan 16 yaitu:

Cuaca dan Iklim (X9), Sikap, opini dan persepsi terhadap destinasi wisata (X10), dan Komitmen terhadap keluarga (X16).

5. Komponen 5 terdiri atas faktor 20 yaitu:

Transportasi dan Akses Jalan (X20)

6. Komponen 6 terdiri atas faktor 12 dan 17 yaitu:

Pengetahuan saat ini tentang Destinasi Wisata (X12) dan Kesehatan personal (X17). 7. Komponen 7 terdiri atas faktor 23 dan 24 yaitu:

Event dan hiburan di destinasi wisata (X23) dan Teknologi Pendukung seperti Internet dan teknologi informasi lainnya (X24). 
Tabel 3 Rotated Component Matrix ${ }^{a}$

\begin{tabular}{|c|c|c|c|c|c|c|c|}
\hline & 1 & 2 & 3 & $\begin{array}{c}\text { Component } \\
4 \\
\end{array}$ & 5 & 6 & 7 \\
\hline$\overline{\mathrm{F} 1}$ & .426 & .468 & .463 & .045 & -.196 & -.027 & .024 \\
\hline F2 & .367 & .080 & .662 & .048 & -.049 & .140 & .109 \\
\hline F3 & .027 & -.009 & .783 & .114 & .312 & .129 & .057 \\
\hline F4 & -.037 & .224 & .663 & .389 & .016 & .153 & .072 \\
\hline F5 & .693 & .137 & .275 & .021 & -.029 & .096 & .163 \\
\hline F6 & .649 & .188 & .218 & .057 & .172 & .164 & .024 \\
\hline F7 & .634 & .096 & -.021 & .444 & -.041 & .039 & .189 \\
\hline F8 & .523 & .053 & -.089 & .249 & .104 & .443 & .082 \\
\hline F9 & .057 & .205 & .157 & .767 & .058 & .154 & .032 \\
\hline F10 & .152 & .092 & .206 & .772 & .013 & -.065 & .194 \\
\hline F11 & -.033 & .774 & -.050 & .111 & -.029 & .256 & .084 \\
\hline F12 & .066 & .197 & .235 & .117 & .001 & .655 & .162 \\
\hline F13 & .372 & .629 & .073 & .174 & -.022 & .234 & .199 \\
\hline F14 & .246 & .508 & .210 & .314 & .254 & .160 & -.011 \\
\hline F15 & .428 & .359 & .384 & .197 & .223 & .263 & -.012 \\
\hline F16 & .202 & .214 & .079 & .484 & .481 & .219 & .000 \\
\hline F17 & .199 & .197 & .195 & -.010 & .094 & .776 & -.023 \\
\hline F18 & .424 & .061 & -.118 & .380 & .354 & .385 & -.202 \\
\hline F19 & .117 & .589 & .249 & .166 & .340 & .068 & .029 \\
\hline F20 & -.054 & .034 & .120 & .043 & .808 & .091 & .048 \\
\hline F21 & .282 & .479 & .119 & .012 & .464 & -.258 & .228 \\
\hline F22 & .575 & .058 & -.050 & -.021 & .563 & -.027 & .189 \\
\hline F23 & .197 & .306 & .229 & .095 & -.072 & .121 & .690 \\
\hline F24 & .119 & -.003 & .000 & .125 & .200 & .027 & .865 \\
\hline
\end{tabular}

Extraction Method: Principal Component Analysis.

Rotation Method: Varimax with Kaiser Normalization.

a. Rotation converged in 16 iterations.

\section{SIMPULAN DAN SARAN}

\section{Simpulan}

Berdasarkan hasil penelitian, dapat disimpulkan bahwa dari 24 faktor-faktor hospitaliti masyarakat yang paling berpengaruh pada kunjungan wisatawan di Kota Bogor dapat dikelompokkan menjadi 7 komponen atau variabel.

\section{Saran}

Dilakukan penggalian lebih dalam terhadap 7 variabel tersebut dengan melakukan penelitian lanjutan.

\section{DAFTAR PUSTAKA}

Assauri, Sofyan. 2002. Manajemen Pemasaran : Dasar, Konsep dan Strategi. Cet : 6 Ed 1. Jakarta: Rajagrafindo Persada.

Dutka, Alan. 1997. AMA Hand book for Customer Satisfaction. NTC
Business Book. Lincolnwood, Illinois.

Gerson, F. Richard. 2004, Mengukur Kepuasan Pelanggan. PPM. Jakarta. Ghozali, Imam. 2000. Aplikasi Analisis Multivariate Dengan Program SPSS. Edisi Ketiga. Solo : Badan Penerbit Universitas Diponegoro.

Goeldner, Charles \& Ritchie, J.R. Brent. (2012). Tourism Principles,

Practices, Philosopies. 12 ${ }^{\text {th }}$ Edition. John Wiley \& Sons,Inc. New Jersey. USA

Husein, Umar. 2003, Metode Riset Perilaku Konsumen Jasa, Jakarta : PT. Gramedia Pusaka Utama.

Kotler, Phillip \& Keller, Kevin L. (2009). Manajemen Pemasaran Edisi Ketiga Belas. Penerbit Erlangga. Jakarta 
Resista Vikaliana, Analisis Faktor Hospitaliti Masyarakat Terhadap Wisatawan...

Schiffman, Leon \& Kanuk, L,Leslie.(2008).Perilaku Konsumen $7^{\text {th }}$ Edition. PT. Indeks. Jakarta

Simamora, Bilson.(2002). Panduan Riset Perilaku Konsumen. Penerbit PT. Gramedia Pustaka Utama. Jakarta

Supranto. 1997. Pengukuran Tingkat Kepuasan Pelanggan Untuk Menaikkan Pangsa Pasar. Jakarta : PT. Rineka Cipta.

Susiyana, Anita Oktarini. 2008.Spirit Publik. Analisis Segmentasi dan Loyalitas Merek dari Pelanggan Telepon selular Berbasis CDMA. Vol.2 No.1. April 2008. Hal 1-6.

Tjiptono, Fandy. 1997. Total Quality Service. Jakarta : Gramedia.

Tjiptono, Fandy. 2002. Strategi Pemasaran.Edisi Kedua.
Yogyakarta : Andi Offset.Yusuf, Muhammad Affandi. 2007. "Faktor yang Mempengaruhi Konsumen Dalam Membeli Kartu Perdana”. Skripsi. Depok: FE UG Depok.

Situs Internet Rujukan :

http://aboutandri.blogspot.com/2005/10/peran g-bisnis-seluler-belum-selesai.html http://hafidzuddin-wordpress.com/ http://elibrary.mb.ipb.ac.id/gdl.php?mod=bro wse \&op=read\&id=mbipb12312421421421412-anitaoktar541

http://bogor.tribunnews.com/2017/03/05/puny a-potensi-besar-promosi-pariwisata-kotabogor-kurang-maksimal Minggu, 5 Maret 2017 15:39 